\title{
Author Correction: Plant pan-genomes are the new reference
}

Philipp E. Bayer (D), Agnieszka A. Golicz, Armin Scheben (1), Jacqueline Batley (D) and David Edwards (1)

Correction to: Nature Plants https://doi.org/10.1038/s41477-020-0733-0, published online 20 July 2020.

In the version of this Review Article originally published, there were a number of duplicated references in the reference list: 11 was a duplicate of 7, 12 was a duplicate of 9, 30 was a duplicate of 27,32 was a duplicate of 15,33 was a duplicate of 20,34 was a duplicate of 17,35 was a duplicate of 24,37 was a duplicate of 22,38 was a duplicate of 26 and 39 was a duplicate of 29. In addition, in the sentence beginning "Differences between clustered and unclustered...', 'B. oleracea' should have been 'Latuca sativa.' These errors have now been amended.

Published online: 2 November 2020

https://doi.org/10.1038/s41477-020-00776-y

(c) The Author(s), under exclusive licence to Springer Nature Limited 2020 